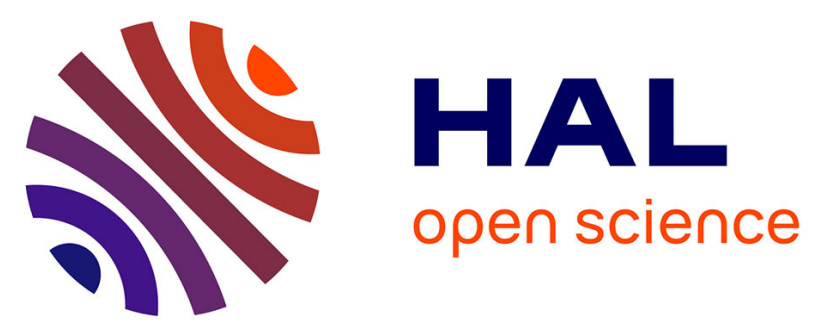

\title{
Part of quercetin absorbed in the small intestine is conjugated and further secreted in the intestinal lumen
}

Vanessa Crespy, Christine Morand, Claudine Manach, Catherine Besson, Christian Demigné, Christian Remesy

\section{- To cite this version:}

Vanessa Crespy, Christine Morand, Claudine Manach, Catherine Besson, Christian Demigné, et al.. Part of quercetin absorbed in the small intestine is conjugated and further secreted in the intestinal lumen. AJP - Gastrointestinal and Liver Physiology, 1999, 277 (1), pp.G120-G126. hal-02697243

\section{HAL Id: hal-02697243 \\ https://hal.inrae.fr/hal-02697243}

Submitted on 1 Jun 2020

HAL is a multi-disciplinary open access archive for the deposit and dissemination of scientific research documents, whether they are published or not. The documents may come from teaching and research institutions in France or abroad, or from public or private research centers.
L'archive ouverte pluridisciplinaire HAL, est destinée au dépôt et à la diffusion de documents scientifiques de niveau recherche, publiés ou non, émanant des établissements d'enseignement et de recherche français ou étrangers, des laboratoires publics ou privés. 
Vanessa Crespy, Christine Morand, Claudine Manach, Catherine Besson, Christian

Demigne and Christian Remesy

Am J Physiol Gastrointest Liver Physiol 277:120-126, 1999.

You might find this additional information useful...

This article cites 23 articles, 4 of which you can access free at:

http://ajpgi.physiology.org/cgi/content/full/277/1/G120\#BIBL

This article has been cited by 14 other HighWire hosted articles, the first 5 are:

Flavonoid metabolites and susceptibility of rat lipoproteins to oxidation

S. Benito, S. Buxaderas and M. T. Mitjavila

Am J Physiol Heart Circ Physiol, December 1, 2004; 287 (6): H2819-H2824.

[Abstract] [Full Text] [PDF]

The splanchnic metabolism of flavonoids highly differed according to the nature of the compound

V. Crespy, C. Morand, C. Besson, N. Cotelle, H. Vezin, C. Demigne and C. Remesy

Am J Physiol Gastrointest Liver Physiol, June 1, 2003; 284 (6): G980-G988.

[Abstract] [Full Text] [PDF]

Metabolism of Flavonoids via Enteric Recycling: Role of Intestinal Disposition

J. Chen, H. Lin and M. Hu

J. Pharmacol. Exp. Ther., March 1, 2003; 304 (3): 1228-1235.

[Abstract] [Full Text] [PDF]

Reply to Arts, Sesink and Hollman

S. Wolffram

J. Nutr., September 1, 2002; 132 (9): 2824-2824.

[Full Text] [PDF]

Evidence for lack of absorption of soy isoflavone glycosides in humans, supporting the crucial role of intestinal metabolism for bioavailability

K. D. Setchell, N. M Brown, L. Zimmer-Nechemias, W. T Brashear, B. E Wolfe, A. S Kirschner and J. E Heubi

Am J Clin Nutr, August 1, 2002; 76 (2): 447-453.

[Abstract] [Full Text] [PDF]

Medline items on this article's topics can be found at http://highwire.stanford.edu/lists/artbytopic.dtl on the following topics:

Biochemistry .. Sulfatases

Biochemistry .. Hydrolysis

Medicine .. Small Intestine

Physiology .. Jejunum

Veterinary Science .. Ileum

Physiology .. Rats

Updated information and services including high-resolution figures, can be found at:

http://ajpgi.physiology.org/cgi/content/full/277/1/G120

Additional material and information about AJP - Gastrointestinal and Liver Physiology can be found at: http://www.the-aps.org/publications/ajpgi

This information is current as of November 15, 2010 .

AJP - Gastrointestinal and Liver Physiology publishes original articles pertaining to all aspects of research involving normal or abnormal function of the gastrointestinal tract, hepatobiliary system, and pancreas. It is published 12 times a year (monthly) by the American Physiological Society, 9650 Rockville Pike, Bethesda MD 20814-3991. Copyright ( 1999 by the American Physiological Society. ISSN: 0193-1857, ESSN: 1522-1547. Visit our website at http://www.the-aps.org/. 


\title{
Part of quercetin absorbed in the small intestine is conjugated and further secreted in the intestinal lumen
}

\author{
VANESSA CRESPY, CHRISTINE MORAND, CLAUDINE MANACH, \\ CATHERINE BESSON, CHRISTIAN DEMIGNE, AND CHRISTIAN REMESY \\ Laboratoire des Maladies Métaboliques et des Micronutriments, Institut National de la \\ Recherche Agronomique de Clermont-Ferrand/ Theix, 63122 Saint Genès Champanelle, France
}

\begin{abstract}
Crespy, Vanessa, Christine Morand, Claudine Manach, Catherine Besson, Christian Demigne, and Christian Remesy. Part of quercetin absorbed in the small intestine is conjugated and further secreted in the intestinal lumen. Am. J . Physiol. 277 (Gastrointest. Liver Physiol. 40): G120-G126, 1999.-Rutin and quercetin absorption and metabol ism were investigated in rats after in situ perfusion of jejunum plus ileum ( $15 \mathrm{nmol} / \mathrm{min}$ ). I n contrast to rutin, a high proportion of quercetin (two-thirds) disappeared during perfusion, reflecting extensivetransfer into the intestinal wall. Net quercetin absorption was not complete $(2.1 \mathrm{nmol} / \mathrm{min})$, inasmuch as $52 \%$ were reexcreted in the lumen as conjugated derivatives (7.7 nmol/min). E nterohepatic recycling contribution of flavonoids was excluded by catheterization of the biliary duct before perfusion. After a 30-min perfusion period, $0.71 \mu \mathrm{M}$ of quercetin equivalents were detected in plasma, reflecting a significant absorption from the small intestine. The differential hydrolysis of effluent samples by glucuronidase and/or sulfatase indicates that the conjugated forms released in the lumen were 1 ) glucuronidated derivatives of quercetin and of its methoxylated forms (64\%) and 2) sulfated form of quercetin (36\%). In vitro quercetin glucuronides synthetized using jejunal and ileal microsomal fractions were similar to those recovered in the effluent of perfusion. These data suggest that glucuronidation and sulfatation take place in intestinal cells, whereas no glucurono-sulfoconjugates could be detected in the effluent. The present work shows that a rapid quercetin absorption in the small intestine is very effective together with its active conjugation in intestinal cells.
\end{abstract}

conjugation; flavonal

FLAVONOIDS ARE A LARGE family of more than 4,000 secondary plant metabolites, comprising anthocyanins, flavonols, flavones, catechines, and flavonones (10). They occur ubiquitously in fruits, vegetables, nuts, seeds, and bark, which are the main dietary sources (14). Therefore they constitute an integral part of the human diet, even though they are considered nonnutrients. Many studies have been drawn toward the beneficial properties of quercetin, the most abundant flavonol in vegetables and fruits (34), namely antibacterial, antiviral, antioxidant, antiproliferative, anti-inflammatory, and anticarcinogenic effects (5, 17, 23, 24). However, the metabolism of this molecule in mammals has not been well characterized. After oral administration of $\left[{ }^{14} \mathrm{C}\right.$ ]quercetin to rats, it has been reported that $20 \%$

The costs of publication of this article were defrayed in part by the payment of page charges. The article must therefore be hereby marked "advertisement" in accordance with 18 U.S.C. Section 1734 solely to indicate this fact. was directly absorbed, 30\% was excreted unchanged in feces, and the remaining was metabolized to various compounds such as $\mathrm{CO}_{2}$ and phenolic acids (30). Phenolic acids, resulting from the ring fission of quercetin by the intestinal microflora $(1,20)$, are extensively recovered in urine of rats after administration of quercetin or rutin (quercetin-3-O-glucose-rhamnose) (4). Moreover, recent in vitro studies, performed using human Caco-2 monolayer cultures, have demonstrated an effective and rapid absorption of quercetin (32). Moreover, many questions remain about the fate of quercetin in the organism. In previous studies, it was found that free quercetin could not be detected in blood plasma, whereas conjugated forms of quercetin (glucurono-sulfated and/or methoxylated forms) were identified $(15,18)$. These metabolites are eliminated via the biliary and urinary pathways $(9,28,35)$. Excreted in the bile, they flow in the small intestine and they reach the hindgut where they can be hydrolyzed by the $\beta$-glucuronidase and sulfatase activities of the microflora, which affords possibilities of enterohepatic cycling $(8,11)$. The main site for quercetin metabolism is the liver, which possesses conjugation activities (UDPglucuronosyltransferase, catechol O-methyltransferase, and sulfotransferase) $(7,28)$. Nevertheless, other tissues, such as kidneys and intestinal mucosa, can also metabolize quer cetin $(12,13,19,31)$.

Therefore, the aim of the present work was to investigate in the rat 1 ) the absorption of quercetin and rutin (one of the glysosylated forms of quercetin found in plant foods) by the small intestine (jejunal and ileal segments) in situ and 2) the metabolism of these compounds by the intestinal mucosa.

\section{MATE RIALS AND METHODS}

\section{Chemicals}

Diosmetin, isorhamnetin, and tamarixetin were purchased from Extrasynthese (Genay, France). Quercetin, rutin, $\beta$-glucuronidase (and sulfatase) from Helix pomatia (type H2), $\beta$-glucuronidasefrom bovineliver, and sulfatasefrom Aerobacter aerogenes were purchased from Sigma (L'Isle D'Abeau, Chesnes, France).

\section{Animals and Diets}

Sixteen male Wistar rats weighing $\sim 150 \mathrm{~g}$ were housed two per cage in temperature-controlled rooms $\left(22^{\circ} \mathrm{C}\right)$, with a dark period from 0800 to 2000 and access to food from 0800 to 1600 . They were fed a standard semipurified diet (73\% wheat starch, $15 \%$ casein, $6 \%$ mineral mixture, $1 \%$ vitamin mixture, and $5 \%$ corn oil) for 2 wk.

Animals were maintained and handled according to the recommendations of the Institut National de la Recherche 
Agronomique Ethics Committee, in accordance with decree no. 87-848.

\section{Sampling Procedure}

Rats were anesthetized with pentobarbital sodium (40 $\mathrm{mg} / \mathrm{kg}$ body wt) $18 \mathrm{~h}$ after the beginning of the meal and maintained alive during the perfusion period.

After cannulation of the biliary duct, a perfusion of jejunal plus ileal segment of intestine $(5 \mathrm{~cm}$ distal from the flexura duodenojejunalis to the valvula ileocecalis) was prepared by installing cannulas (external diam $4 \mathrm{~mm}$, internal diam 2.5 $\mathrm{mm}$ ) at each extremity. This segment was continuously perfused in situ with a buffer containing (in $\mathrm{mM}$ ) $2.5 \mathrm{KH}_{2} \mathrm{PO}_{4}$, $2.5 \mathrm{~K}_{2} \mathrm{HPO}_{4}, 5 \mathrm{NaHCO}_{3}, 50 \mathrm{NaCl}, 50 \mathrm{KCl}, 2 \mathrm{CaCl}_{2}, 2 \mathrm{MgCl}_{2}$, 2.5 HEPES Na, 2.5 HEPES acid, pH 6.7, 8 glucose, and 1 taurocholic acid at a flow rate of $1 \mathrm{ml} / \mathrm{min}$, at $37^{\circ} \mathrm{C}$, and supplemented with $15 \mu \mathrm{M}$ of quercetin or rutin. An aliquot of effluent was directly collected at the exit of the ileum in plastic tubes $(1.5 \mathrm{ml})$ during the last $5 \mathrm{~min}$ of perfusion. The bile was collected all al ong the perfusion step.

At the end of the experiment, blood samples were withdrawn from the abdominal aorta into heparinized tubes. Plasma, bile, and perfusate samples were acidified with 10 $\mathrm{mM}$ acetic acid and then stored at $-20^{\circ} \mathrm{C}$.

\section{HPLC Analysis}

Samples treatment. Plasma and bile were spiked with 3.5 $\mu \mathrm{mol} / \mathrm{l}$ of diosmetin (final concentration) used as an internal standard and acidified (to $\mathrm{pH} 4.9$ ) with 0.1 vol of acetic acid, $0.58 \mathrm{M}$. The samples were treated for $30 \mathrm{~min}$ at $37^{\circ} \mathrm{C}$ with $5 \times$ $10^{6} \mathrm{U} / \mathrm{l} \beta$-glucuronidase and $2.5 \times 10^{5} \mathrm{U} / \mathrm{l}$ sulfatase (for visualizing the total forms). The reactions were stopped by addition of $2.85 \mathrm{vol}$ of acetone, and the resulting mixtures were centrifuged. This procedure was sufficient to totally extract quercetin bound to plasma albumin $(6,16)$. After this extraction step, $20 \mu$ of supernatant were injected and analyzed by HPLC.

Effluent samples $(100 \mu \mathrm{l})$ were acidified with $0.1 \mathrm{vol}$ of acetic acid, $0.58 \mathrm{M}$, and directly analyzed or treated as follows: 1) incubated for $30 \mathrm{~min}$ at $37^{\circ} \mathrm{C}$ with $50 \mathrm{U} \beta$-glucuronidase and $2.5 \mathrm{U}$ sulfatase from Helix pomatia, 2) incubated for $120 \mathrm{~min}$ at $37^{\circ} \mathrm{C}$ with $1,000 \mathrm{U}$ of bovine $\beta$-glucuronidase, and 3) incubated for $240 \mathrm{~min}$ at $37^{\circ} \mathrm{C}$ with $50 \mathrm{U}$ of aryl sulfatase from A. aerogenes.

In each case, the reactions were stopped by adding $150 \mu \mathrm{l}$ of acetone. After centrifugation, a $20-\mu \mathrm{l}$ aliquot of supernatant was injected in the HPLC system for analysis. The concentrations in conjugated derivatives present in a sample were estimated as the difference between the concentrations of quercetin recorded before and after the adequate enzymatic treatment.

Chromatographic conditions. The HPLC system used consisted of an autosampler (Kontron 360), an ultraviolet detector (set at $370 \mathrm{~nm}$ ), and a software system for data recording and processing. The system was fitted with a $5-\mu \mathrm{m} \mathrm{C}-18$ Hypersil based deactivated silica analytical column $(150 \times$ $4.6 \mathrm{~mm}$; Life Sciences International, Cergy, France). The mobile phase consisted of water and $\mathrm{H}_{3} \mathrm{PO}_{4}$ (99.5:0.5, solvent A) and acetonitrile (solvent B ).

To separate the conjugated metabolites of flavonoids, the chromatographic conditions were as follows (flow rate 1 $\mathrm{ml} / \mathrm{min}$ ): 0-2 min solvent A 85\%/solvent B 15\%; 2-22 min solvent A $85 \% /$ solvent $B 15 \% \rightarrow$ solvent A $60 \% /$ solvent $B \quad 40 \%$; 22-24 min sol vent A 60\%/solvent B 40\%; 24- 27 min return to initial mobile phase conditions and then equilibration for 8 $\min$.

\section{In Vitro Assay of Flavonoid Glucuronidation}

J ejunal and ileal microsomes from rat intestine were prepared by differential ultracentrifugation at $105,000 \mathrm{~g}$ at $4^{\circ} \mathrm{C}$ for $1 \mathrm{~h}$. To prepare intestinal microsomes, mucosal scraping (50 cm for jejunal and $20 \mathrm{~cm}$ for ileal intestine) were homogenized in ice-cold buffer containing Tris. $\mathrm{HCl}(50 \mathrm{mM}$, $\mathrm{pH}$ 7.2), sucrose (100 mM), EDTA (10 mM), dithiothreitol (2 $\mathrm{mM})$, leupeptin $(1 \mu \mathrm{M})$, and trypsin inhibitor $(25 \mathrm{mg} / 100 \mathrm{ml})$. The final microsomal pellet was suspended in a buffer containing HEPES (100 mM ), pH 7.2, sucrose (100 mM), and trypsin inhibitor $(25 \mathrm{mg} / 100 \mathrm{ml})$ and kept in a frozen state at $-20^{\circ} \mathrm{C}$ until use. The preparations were adjusted to have a final protein concentration of about $5 \mathrm{mg} / \mathrm{ml}$, measured according to the Pierce bicinchoninic acid protein reagent kit (Interchim, Montluçon, France).

I ncubations were carried out as follows. I $\mathrm{n}$ a final volume of $750 \mu \mathrm{l}, 540 \mu \mathrm{l}$ of buffer (HEPES, $75 \mathrm{mM}, \mathrm{pH} 7.3, \mathrm{MgCl}_{2}, 10$ $\mathrm{mM}), 50 \mu \mathrm{l}$ of UDP-glucuronic acid (4.5 mM final), and $100 \mu \mathrm{l}$ of microsomal suspension ( $50 \mu \mathrm{g}$ protein) were activated in situ by $60 \mu$ of a $0.2 \%$ solution of Triton X-100. The reaction was started by the addition of $2 \mu \mathrm{l}$ of quercetin (18.75 mM in DMSO). I ncubations were performed at $37^{\circ} \mathrm{C}$ for $3 \mathrm{~h}$, and then aliquots of the reaction mixture were taken and treated [with or without $\beta$-glucuronidase (and sulfatase)] for HPLC analysis, exactly as previously decribed.

Statistics

Values are means $\pm \mathrm{SE}$, and the differences between values were determined by one-way ANOVA coupled with the Student-Newman-Keuls multiple-comparison test. Values of $\mathrm{P}<$ 0.05 were considered significant.

\section{RESULTS}

Comparison of In Situ Intestinal Perfusion of Rutin and Quercetin in Rats

When the intestine was perfused at a flow rate of 1 $\mathrm{ml} / \mathrm{min}$ during $30 \mathrm{~min}$ with a buffer containing $15 \mu \mathrm{M}$ rutin, the concentrations of this glycoside in the effluent collected at the extremity of the ileum were not significantly different from those initially present in the perfusate (Fig. 1). This indicates that rutin is not noticeably absorbed nor metabolized by the intestinal wall.

By contrast, when quercetin was perfused in the jejunoileal segment (at $14.7 \pm 0.6 \mu \mathrm{M}$, with a flow rate of $1 \mathrm{ml} / \mathrm{min}$ ), the concentration of this flavonol (free and conjugated forms) in the residual perfusate was significantly decreased (12.6 $\pm 0.2 \mu \mathrm{M}$; Fig. 1). Thus $14.3 \%$ of perfused quercetin was taken up by the intestinal wall. Moreover, in plasma hydrolyzed by $\beta$-glucuronidase (and sulfatase), the concentration of quercetin was about $0.71 \pm 0.06 \mu \mathrm{M}$ (Table 1 ), giving additional evidence for the absorption of quercetin through the intestinal wall. Preliminary experiments have established that before perfusion no trace of quercetin was present in rat plasma (data not shown).

\section{Differential Hydrolysis of Effluent Resulting From Intestinal Perfusion of Quercetin}

The representative HPLC profile of the nonhydrolyzed effluent (Fig. 2A) is characterized by 1 ) a peak of quercetin at a concentration of $4.9 \pm 0.4 \mu \mathrm{M}$ (indicating 


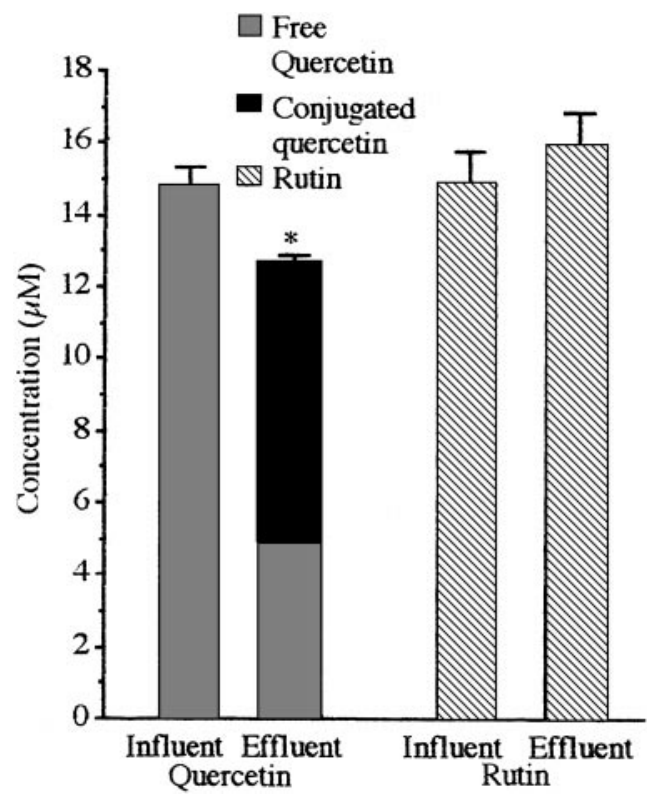

Fig. 1. Change in quercetin and rutin concentrations after perfusion of rat intestine. Quercetin and rutin concentrations were determined from HPLC as described in MATERIALS AND METHODS. Samples were hydrolyzed by $\beta$-glucuronidase (and sulfatase) to rel ease aglycones or nonhydrolyzed to visualize conjugated forms. Data are means $\pm \mathrm{SE}$, $\mathrm{n}=8$ for each group. $* \mathrm{P}<0.05$ influent vs. effluent.

that $\sim 33 \%$ of infused quercetin was not metabolized by theintestinal cells) and 2) the presence of five unidentified peaks. Four of these peaks (1-4) totally disappeared after hydrolysis of the samples with $\beta$-glucuronidase (and sulfatase) from Helix pomatia (Fig. 2B), suggesting that they corresponded to quercetin conjugates. This HPLC profile (Fig. 2B) was also characterized by the presence of two small peaks (at $24.47 \mathrm{~min}$ and $24.72 \mathrm{~min}$ ) corresponding, respectively, to trace amounts of isorhamnetin (about $0.2 \mu \mathrm{M}$ ) and tamarixetin $(<0.1 \mu \mathrm{M})$, the methoxylated forms of quercetin. Moreover, the treatment of the effluent with the $\beta$-glucuronidase (and sulfatase) extract induced only a $50 \%$ decrease in the intensity of peak 5 (Fig. 2B), whereas this peak totally disappeared when the effluent was hydrolyzed by a sulfatase from A. aerogenes (Fig. 2C). This indicates that peak 5 should represent sulfoconjugate which is only partially hydrolyzed by the

Table 1. Quercetin and quercetin derivative concentrations in various biological samples after perfusion of rat intestine with quercetin

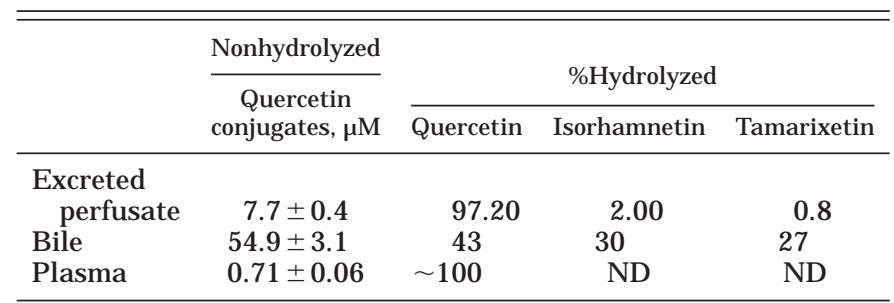

Values are means $\pm \mathrm{SE} ; \mathrm{n}=8$ rats. ND, not detectable. Conjugated forms, glucuronosulfo derivates of quercetin and of its methoxylated forms. Amounts of conjugated derivatives were calculated by substracting conjugate values from total ones. sulfatase component present in the Helix pomatia extract.

When the effluent was treated with the sulfatase al one (Fig. 2C), no trace of isorhamnetin and tamarixetin was detected in this fraction, and the concentration of quercetin was estimated at $7.7 \pm 0.4 \mu \mathrm{M}$. This indicates that the methoxylated forms of quercetin were not sulfated in the intestine and that the sulfate derivative of quercetin corresponded to $2.8 \pm 0.3 \mu \mathrm{M}$ of quercetin equivalent (calculated as the difference between the concentration of quercetin measured before and after the enzymatic treatment).

The hydrolysis of the effluent with bovine $\beta$-glucuronidase led to a complete disappearence of peaks 1-4 (Fig. 2D), whereas peak 5 was unaffected and the resulting concentration of quercetin was about $9.8 \pm 0.6 \mu \mathrm{M}$. In such conditions, the concentration in quercetin glucuronides present in the effluent was estimated to be about $4.9 \pm 0.2 \mu \mathrm{M}$. Moreover, isorhamnetin $(\sim 0.2 \mu \mathrm{M})$ and tamarixetin $(<0.1 \mu \mathrm{M})$ are present in Fig. $2 \mathrm{D}$, indicating that these compounds are submitted to an intestinal glucuronidation.

The total concentration of quercetin recovered in the hydrolyzed effluent was $12.6 \pm 0.2 \mu \mathrm{M}, 4.9 \pm 0.2 \mu \mathrm{M}$ (namely 39\%) being unconjugated forms of quercetin and $7.7 \pm 0.4 \mu \mathrm{M}$ (namely 61\%) being conjugated derivatives. These conjugates are composed of $36 \%$ sulfate derivatives and $64 \%$ glucuronides; a minor part of them could be methoxylated.

\section{Quercetin Fluxes After Intestinal Perfusion}

Whereas the total flux of quercetin in the perfusion was $14.7 \pm 0.6 \mathrm{nmol} / \mathrm{min}$ (flow rate $1 \mathrm{ml} / \mathrm{min}$ ), only $4.9 \pm 0.4 \mathrm{nmol} / \mathrm{min}$ of quercetin was recovered intact in the effluent. The secretion of conjugated derivatives from the wall into the lumen could explain why the net absorption of quercetin was low compared with its total transfer into the intestinal wall (Fig. 3). By contrast, the net flux of quercetin absorption $(2.1 \pm 0.4 \mathrm{nmol} / \mathrm{min}$ corresponding to $14.3 \%$ of total perfused quercetin) was markedly lower than the secretion flux of conjugates from the wall into the lumen $(7.7 \pm 0.4 \mathrm{nmol} / \mathrm{min}$, namely $52.4 \%$ of total perfused quercetin) (Fig. 3). The sum of these fluxes corresponded to the net transfer of quercetin into the intestinal wall $(9.8 \pm 0.5 \mathrm{nmol} / \mathrm{min})$. Therefore, $78.5 \%$ of absorbed quercetin was directly conjugated and eliminated by the intestine. In comparison to intestinal secretion, the biliary secretion flux was quitelimited (Fig. 3).

\section{In Vitro Glucuronidation of Quercetin by Intestinal Wall}

The in vitro capacity of rat jejunal and ileal fractions to transfer glucuronic acid from UDP-glucuronic acid to quercetin has been tested using microsomal preparations. It could be noted that the capacity of the jejunal wall to conjugate quercetin appeared significantly greater than that of the ileal wall (Fig. 4); the percentage of total quercetin metabolized in the jejunum microsomal fraction was 43 vs. $32 \%$ in ileal one. In both 

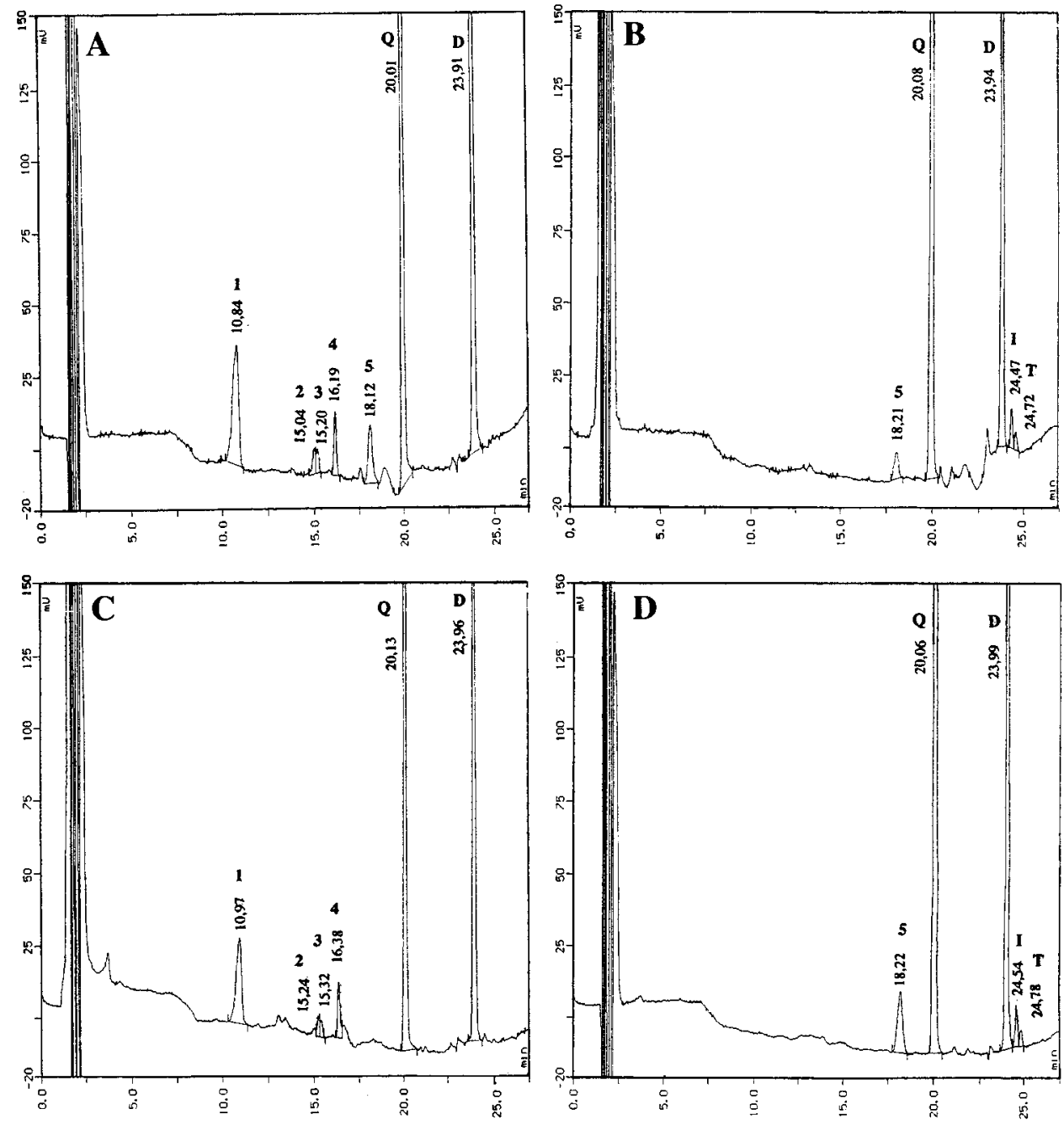

Fig. 2. RepresentativeHPLC chromatograms of intestinal effluent after 30 min perfusion with solution containing $15 \mu \mathrm{M}$ quercetin (flow rate of $1 \mathrm{ml} / \mathrm{min}$ ) nonhydrolyzed (A) or hydrolyzed with $\beta$-glucuronidase (and sulfatase) from Helix pomatia (B), aryl sulfatase from Aerobacter aerogenes (C), and bovine $\beta$-glucuronidase (D). D, diosmetin (internal standard); Q, quercetin; I, isorhamnetin; T, tamarixetin; 1, 2, 3, 4, 5, conjugated metabolites of quercetin. cases, the same four metabolites (referred to as a-d, according to their increasing hydrophobicity) were present on the HPLC profiles (Fig. 4). These peaks corresponded to the glucuronidated forms of quercetin.

The HPLC profile of nonhydrolyzed effluent resulting from quercetin perfusion (Fig. 2A) has been compared with that obtained after in vitro glucuronidation of quercetin by microsomal jejunal and ileal fractions (Fig. 4). By taking into account the respective relative retention times compared with diosmetin, peaks 1, 2, and 4 (Fig. 2A) exhibited a perfect coincidence with those noted b, c, and d, obtained by the in vitro glucuronidation procedure (Fig. 4). Peak 3 could correspond to glucuronidated-methoxylated forms of quercetin (but this point was not tested). These data support the view of the existence of an UDP-glucuronyltransferase activity using quercetin as a substrate at the intestinal level.

\section{Concentrations of Quercetin and of I ts Methoxylated Forms in Various Biological Samples}

At the end of the perfusion period, the concentration of quercetin in hydrolyzed plasma was about $0.71 \pm$ $0.06 \mu \mathrm{M}$ (Table 1). By contrast, in nonhydrolyzed plasma no trace of free quercetin could be found, indicating that the circulating forms of quercetin are glucurono-sulfoconjugates. However, these quercetin metabolites were not detected in nonhydrolyzed samples, probably because their responsiveness was too low in the present chromatographic conditions (Table 1).

In all experiments a cannulation of the biliary duct was performed to test the enterohepatic cycling of quercetin. The biliary secretion was quite noticeable at the end of the perfusion; about $55 \mu \mathrm{M}$ of quercetin and of its methoxylated forms were found in the hydrolyzed bile samples. Quercetin constituted the main form of biliary excretion (43\%), the other metabolites being isorhamnetin and tamarixetin (30 and 27\%, respectively) (Table 1). This high level of biliary excretion accounts for a very active hepatic metabolism of quercetin.

\section{DISCUSSION}

In the present experimental pattern, rutin was not absorbed and metabolized in the small intestine. These data are in accordance with those of Manach et al. (16), which showed that the absorption of rutin was delayed 


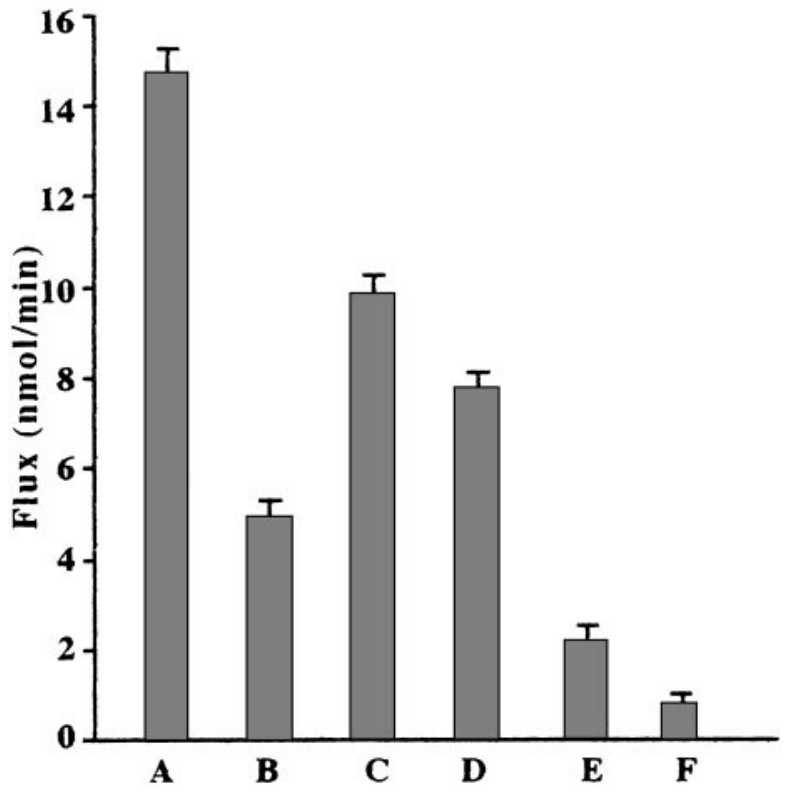

Fig. 3. Quercetin fluxes in different biological samples after intestinal infusion. Data are means $\pm S E ; n=8$. Ileal plus jejunal segments were perfused with $15 \mu \mathrm{M}$ quercetin for $30 \mathrm{~min}$ at flow rate of 1 $\mathrm{ml} / \mathrm{min}$ as described in MATERIALS AND METHODS. The present quercetin fluxes have been calculated using data from Fig. 1. Biliary flow rate was $13.6 \pm 0.7 \mu \mathrm{l} / \mathrm{min}$. $A$, quercetin perfusion flux; $B$, free quercetin recovered in effluent; $C$, net transfer of quercetin into intestinal wall; $D$, net secretion of conjugated quercetin from intestinal wall intolumen; $E$, effectiveabsorption of quercetin; $F$, biliary flux of conjugated forms. compared with that of quercetin. I ndeed, the hydrolysis of rutin takes place in the cecum because the microflora possesses glycosidases liable to hydrolyze glycosides with a high degree of specificity (3). Then the free quercetin produced can be absorbed, eliminated, or degraded in phenolic acids $(1,4,30)$.

In contrast to rutin, the absorption of quercetin from the small intestine appears very effective, inasmuch as $66.7 \%$ of perfused quercetin is absorbed by the small intestine, although the perfusion rate is relatively high $(0.9 \mu \mathrm{mol} / \mathrm{h}$ of quercetin, which after extrapolation represents $6.5 \mathrm{mg} /$ day). A recent study deal ing with the transcellular transport of quercetin in the intestine using a Caco-2 cell monolayer model (32) corroborates the present finding. The study by Walgren et al. (32) reported that the average recovery in the basolateral side was to $67 \%$ of medium quercetin with an apical loading in this molecule.

A significant part of the quercetin recovered in the effluent was conjugated. These conjugated forms of quercetin have an intestinal origin because the biliary duct was cannulated before the beginning of the perfusion (leading to a disruption of the enter ohepatic cycle). The intestinal metabolism of flavonoids is still poorly known; nevertheless previous studies performed on rats have al ready shown that glucuronide and sulfate forms of 1-naphthol and estrogens were excreted in the lumen during in situ perfusion of the intestine $(2,26)$. Thus the intestinal metabolism of quercetin and that of
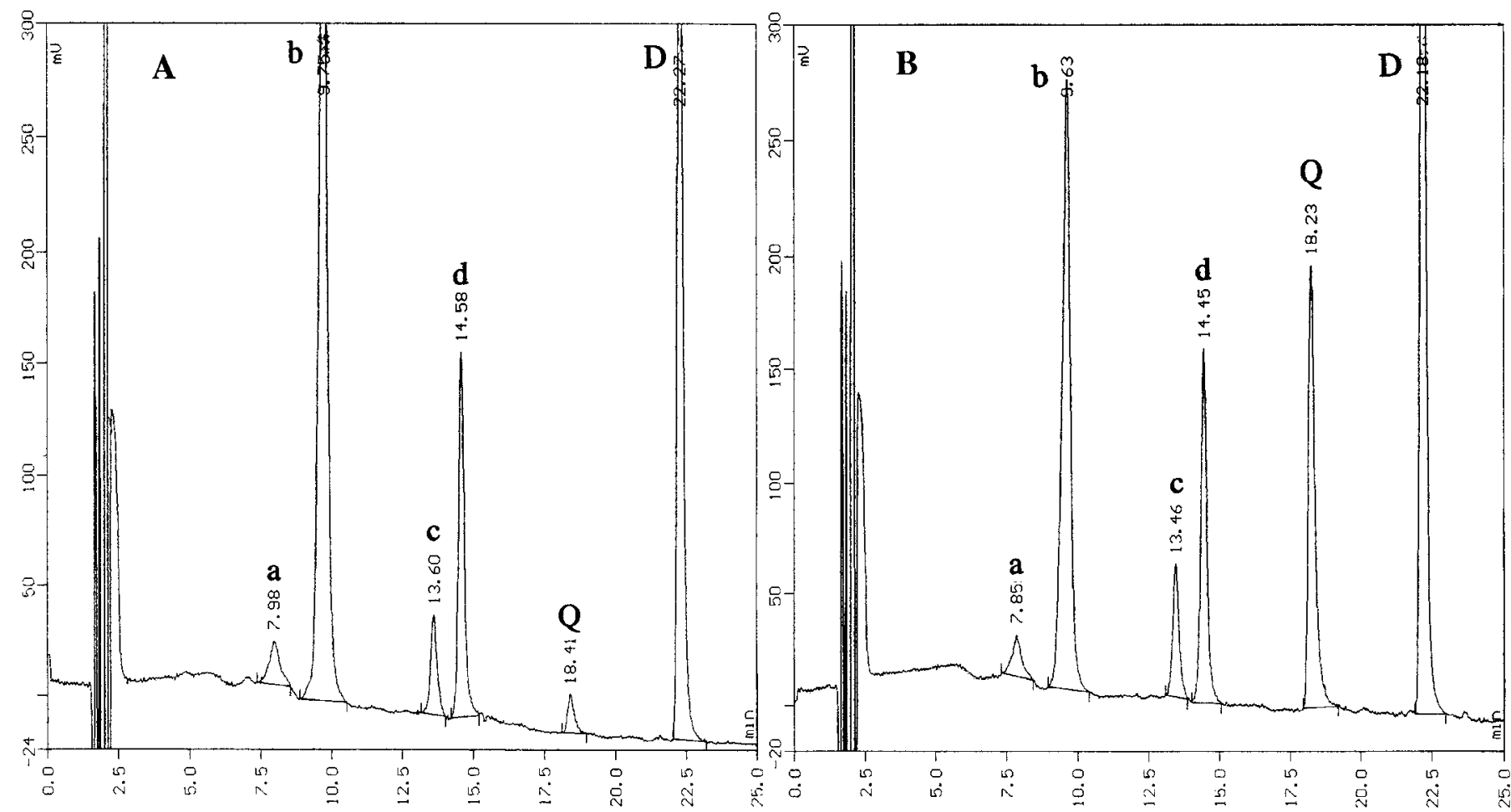

Fig. 4. Representative HPLC chromatograms obtained after glucuronidation of $50 \mu \mathrm{M}$ quercetin with microsomal preparations from jejunum (A) and ileum (B) walls. In vitro glucuronidation procedure was detailed in MATERIALS AND METHODS. After a 3-h incubation period at $37^{\circ} \mathrm{C}$, aliquots of the reaction mixture were directly extracted with acetone and glucuronidated forms of quercetin were visualized by HPLC analysis. Q, quercetin; D, diosmetin (internal standard). a, b, c, d, Glucuronide derivatives. 
these compounds seems quite similar. In view of this, Sfakianos et al. (27) have described an in vivo glucuronidation of an isoflavone (genistein) by the intestinal wall.

The existence of an intestinal UDP-glucuronyltransferase activity was confirmed by the present in vitro experiments of quercetin glucuronidation from jejunal and ileal microsomal preparations. The glucuronidation yield measured on these fractions appears lower than that observed with liver microsomes (18); however, it was still noticeable. Glucuronidation was not the sole conjugative activity present in the intestine since methoxylated forms of quercetin (3- and 4-Omethylquercetin) are released after hydrolysis of the effluents with $\beta$-glucuronidase (and sulfatase). Although the activity of catechol O-methyltransferase has been reported to be maximum in the liver and kidneys (29), it is also present in the enterocytes (21). The cells can combine processes of glucuronidation and methylation. The glucuronidation has been described as a rapid process $(2,22)$ that takes place for the high concentrations of metabolites (12). This could explain why the percentage of glucuronidation in the intestine (64\%) appeared greater than that of methylation (4\%) (12). This result is in accordance with those of Piskula and Terao (21), which showed that the glucuronidation of epicatechin was more important than the methoxylation in the intestine. Moreover, these data have been obtained in vitro, and additional experiments could be performed to test in vivo their validity. In keeping with a previous report (25), the present work shows the existence of a sulfotransferase activity in intestinal cells. It is well established that whatever its origin, the sulfotransferase activity is inversely related to the concentration of quercetin $(25,28,33)$. However, in the present conditions of perfusion, even if the glucuronidation prevailed (64\%), sulfatation was substantial $(36 \%$ of the total conjugation). At the intestinal level, quercetin was sulfated but no trace of mixed glucuronosulfoconjugates was found. By contrast, it has been shown (18) that in rats adapted to a quercetin diet the major circulating forms of quercetin are constituted by glucurono-sulfoconjugates. The absence of these compounds at the intestinal level strongly suggests that they are preferentially synthetized in the liver.

According to the present data and to those found in the literature $(11,15,16,18)$, it could be possible to depict the major features of quercetin absorption and the metabolism at the intestinal level (Fig. 5). Quercetin enters the cells by a still unidentified mechanism. In these cells, quer cetin is readily glucuronidated, methoxylated, and sulfated. The resulting metabolites can subsequently leave the intestinal cell possibly via a facilitated transport system, either across the apical pole (secretion of the conjugated forms in the lumen) or across the basolateral side for their further transfer into the portal vein. However, disposal data are not sufficient to exclude that a part of the absorbed quercetin can circulate in the blood as aglycone (Fig. 5).

The liver further metabolizes the conjugated compounds arising from intestine, leading to an increase of

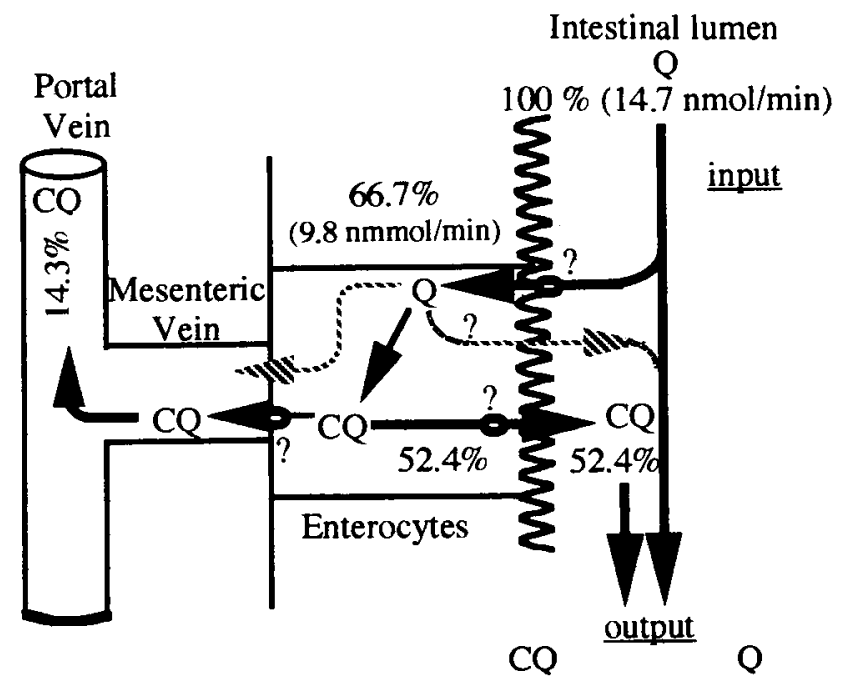

$14.3 \%$

$52.4 \%$

$33.3 \%$

$(7.7 \mathrm{nmol} / \mathrm{min})(4.9 \mathrm{nmol} / \mathrm{min})$

- Transporter

- Mu- Hypothetic flux

of the aglycone form

Fig. 5. Representative schematic of quercetin fate at intestinal level. Present diagram presents quercetin fluxes at intestinal level consecutive to perfusion of jejunoileal segment with quercetin $(14.7 \mathrm{nmol} /$ $\mathrm{min}$ ). In these conditions, $66.7 \%$ of perfused quercetin enters enterocytes by a still unidentified mechanism. In these cells quercetin is readily conjugated; resulting metabolites can leave the intestinal cells either across the apical pole (78.5\%) or across the basolateral side $(21.5 \%)$. In such conditions, $14.3 \%$ of perfused quercetin is recovered in plasma as conjugated derivatives, whereas the remaining conjugates synthetized in the enterocytes (and corresponding to $52.4 \%$ of perfused quercetin) are reexcreted into theintestinal lumen. The effluent also contains free quercetin escaping to intestinal metabolism (33.3\% of perfused dose). However, it could not be ruled out that a part of quercetin absorbed by the enterocytes could be directly reexcreted into the lumen or secreted in the plasma as free form (hatched arrow). Q, quercetin; CQ, conjugates of quercetin.

their degree of glucuronidation, sulfatation, and methoxylation. Thus no trace of free quercetin could be detected in the plasma of rats infused with quercetin in the small intestine. This is in accordance with previous studies, in which it was reported that the circulating metabolites of quercetin recovered in the plasma are glucurono-sul foconjugates with a high degree of methoxylation $(16,18)$. In vitro the rate of intestinal conjugation and of secretion of quercetin metabolites toward the lumen is quite substantial, but in vivo the intestinal secretion of conjugated derivatives could be lower. In vivo the presence of biliary quercetin conjugates in the lumen could decrease the concentration gradient between the enterocytes and the digestive content and therefore the flow of conjugates could be preferentially directed toward the basolateral side.

In the present work, both production and elimination of conjugates seen essentially occur via the intestinal pathway, rather than by the biliary route. Whatever their origin (biliary or intestinal), quercetin conjugates could be recycled after their metabolism by the microflora, in the large intestine (9). This phenomenon can contribute to extend the bioavailability of quercetin all al ong the light-dark cycle (9). However, bacterial degra- 
dation of quercetin into phenolic acids (4) may depress the recovery of the intestinal conjugates.

In conclusion, the intestinal secretion of quercetin conjugates constitutes an elimination pathway that should be taken into account, in addition with the urinary and biliary pathways. Nevertheless, it seems essential to characterize the transport systems for the aglycone and conjugated forms across the intestinal membrane.

Address for reprint requests and other correspondence: V. Crespy, Laboratoire des Maladies Métaboliques et des Micronutriments, I NRA de Clermont-Ferrand/Theix, 63122 Saint Genès Champanelle, France (E-mail: crespy@clermont.inra.fr).

Received 25 September 1998; accepted in final form 12 April 1999.

\section{REFERENCES}

1. Baba, S., T. F uruta, M. Fujioka, and T. Gromaru. Studies on drug metabolism by use of isotopes XXXVII: urinary metabolites of rutin in rats and the role of intestinal microflora in the metabolism of rutin. J. Pharm. Sci. 72: 1155-1158, 1983.

2. Bock, K. W., and D. Winne. Glucuronidation of 1-naphthol in the rat intestinal loop. Biochem. Pharmacol. 24: 859-862, 1975.

3. Bokkenheuser, V. D., C. H. L. Shackleton, and J . Winter. Hydrolysis of dietary flavonoids glycosides by strains of intestinal Bacteroides from humans. Biochem. J . 248: 953-956, 1987.

4. Booth, A. N., C. W. Murray, F. T. J ones, and F. Deeds. The metabolic fate of rutin and quercetin in the animal body. J. Biol. Chem. 233: 251-257, 1956.

5. Bors, W., W. Heller, C. Michel, and K. Stettmaier. Flavonoids and polyphenols: chemistry and biology. In: Handbook of Antioxydants, edited by E. Cadenas, and L. Packer. New York: Dekker, 1996, p. 409-466.

6. Boulton, D. W., K. Walle, and T. Walle. Extensive binding of the bioflavonoid quercetin to human plasma proteins. J . Pharm. Pharmacol. 50: 243-249, 1998.

7. Boutin, J. A., J. Thomassin, G. Siest, and A. Cartier. Heterogeneity of hepetic microsomal UDP-glucuronosyltransferase activities. Biochem. Pharmacol. 34: 2235-2249, 1985.

8. Griffiths, L. A. Mammalian metabolism of flavonoids. In: The Flavonoids: Advances in Research, edited by J . B. Harborne and T. J . Mabry. London: Chapman and Hall, 1982, p. 681-718.

9. Hackett, A. M. The metabolism of flavonoid compounds in mammals. In: Plant Flavonoids in Biology and Medicine. Biochemical Pharmacological and Structure Activity Relationships, edited by V. Cody, E. Middleton, J r., and J . B. Harborne. New York: Liss, 1986, p. 177-194.

10. Harborne, J . B. The Flavonoids: Advances in Research Since 1986. London: Chapman and Hall, 1994, p. 329-419.

11. Hollman, P. C. H., and M. B. Katan. Absorption, metabolism, and bioavailability of flavonoids. In: Flavonoids in Health and Disease, edited by C. Rice-Evans and L. Packer. New York: Dekker, 1998, p. 483-523.

12. Koster, A. S. Intestinal glucuronidation. In vivo and in vitro model systems. In: Advances in Glucuronidation Conjugation, edited by S. Mater, K. W. Bock, and W. Gerok. Lancaster, PA: MTP, 1985, p. 177- 198.

13. Koster, A. S., G. Schirmer, and K. W. Bock. I mmunochemical and functional characterization of UDP-glucuronyltranferases from rat liver, intestine and kidney. Biochem. Pharmacol. 35: 3971-3975, 1986.

14. Kühnau, J. The flavonoids. A class of semi-essential food components: their role in human nutrition. World Rev. Nutr. Diet. 24: 117-191, 1976.
15. Manach, C., C. Morand, C. Demignë, O. Texier, F. Régérat, and C. Rémésy. Bioavailability of rutin and quercetin in rats. FEBS Lett. 409: 12-16, 1997.

16. Manach, C., C. Morand, O. Texier, M.-L. Favier, G. Agullo, C. Demigné, F. Régérat, and C. Rémésy. Quercetin metabolites in plasma of rats fed diets containing rutin or quercetin. J . Nutr. 125: 1911-1922, 1995.

17. Middleton, E., J r., and C. Kandaswami. The impact of plant flavonoids on mammalian biology: implications for immunity, inflammation and cancer. In: The Flavonoids: Advances in Re search Since1986, edited by J . B. Harborne. London: Chapman \& Hall, 1994, p. 619-652.

18. Morand, C., V. Crespy, C. Manach, C. Besson, C. Demigne, and C. Remesy. Plasma metabolites of quercetin and their antioxidant properties. Am. J . Physiol. 275 (Regulatory IntegrativeComp. Physiol. 44): R212-R219, 1998.

19. Mulder, G. J ., and W. B. J akoby. Sulfation. In: Conjugation Reactions in Drug Metabolism, edited by G. J . Mulder. London: Taylor \& Francis, 1990, p. 107-161.

20. Nakagawa, Y., M. R. Shetlar, and S. H. Wender. Urinary products from quercetin in neomycin-treated rats. Biochim. Biophys. Acta 97: 233-241, 1965.

21. Piskula, M. K., and J . Terao. Accumulation of (-)-E picatechin in rat of plasma after oral administration and distribution of conjugation enzymes in rat tissues. J. Nutr. 128: 1172-1178, 1998.

22. Powell, G. M., J . J . Miller, A. H. Olavesen, and C. G. Curtis. Liver as major organ of phenol detoxication? Nature 252: 234235, 1974.

23. Rice-Evans, C. A., and N. J . Miller. Antioxidant activities of flavonoids as bioactive components of food. Biochem. Soc. Trans. 24: 790- 795, 1996.

24. Rice-Evans, C. A., N. Miller, and G. Paganga. Antioxidant properties of phenolic compounds. Trends Plant Sci. 2: 152-159, 1997.

25. Runge-Morris, M. A. Regulation of expression of the rodent cytosolic sulfotransferases. FASE B J . 11: 109- 117, 1997.

26. Schwenk, M., C. Schiemenz, C. V. Lopez del Pino, and H. Remmer. First pass biotransformation of ethinylestradiol in rat small intestine in situ. Naunyn Schmi edebergs Arch. Pharmacol. 321: 223-225, 1982

27. Sfakianos, J ., L. Coward, M. Kirk, and S. Barnes. Intestinal uptake and biliary excretion of the isoflavone genistein in rats. J . Nutr. 127: 1260-1268, 1997.

28. Shali, N. A., C. G. Curtis, G. M. Powell, and A. B. Roy. Sulphation of the flavonoids quercetin and catechin by rat liver. Xenobi otica 21: 881-893, 1991.

29. Tilgmann, C., and I. UImanen. Purification methods of mammalian catechol-O-methyltransferases. J . Chromatogr. B. 684: 147-161, 1996.

30. Ueno, I., N. Nakano, and I . Hirono. Metabolic fate of $\left[{ }^{14} \mathrm{C}\right] q u e r-$ cetin in the ACI rat. J apan J . Exp. Med. 53: 41-50, 1983.

31. Vargas, M., and M. R. F ranklin. Intestinal UDP-glucuronosyltransferase activities in rat and rabbit. Xenobiotica 27: 413-421, 1997.

32. Walgren, R. A., U. K. Walle, and T. Walle. Transport of quercetin and its glucosides across human intestinal epithelial Caco-2 cells. Biochem. Pharmacol . 55: 1721-1727, 1998.

33. Walle, T., E.A. E aton, and U. K. Walle. Quercetin, a potent and specific inhibitor of the human P-form phenolsulfotransferase. Biochem. Pharmacol. 50: 731-734, 1995.

34. Wollenweber, E. Flavones, and flavonols. In: The Flavonoids: Advances in Research, edited by J . B. Harborne and T. J . Mabry. London: Chapman and Hall, 1982, p. 189-259.

35. Zhu, B. T., E. L. Ezell, and J. G. Liehr. Catechol-Omethyltransferase-catalysed rapid O-methylation of mutagenic flavonoids. J. Biol. Chem. 1: 292-299, 1994. 